\title{
Epidemiological Estimators' Power of rating Inequality in Health in High-income OECD Countries, 1998-2002
}

\section{Capacidad de estimadores epidemiológicos para medir disparidades en salud en países OCDE de alto Ingreso, 1998-2002}

\author{
Javier Eslava-Schmalbach ${ }^{1}$, Helman Alfonso², Hernando Gaitán ${ }^{3}$ \\ y Carlos Agudelo ${ }^{4}$
}

1 National University of Colombia, Clinical Research Institute. jheslavas@unal.edu.co

2 University of Western Australia, School of Public Health. Helman.Alfonso@uwa.edu.au

3 National University of Colombia, Clinical Research Institute. hggaitand@unal.edu.co

4 National University of Colombia. Institute of Public Health, School of Medicine. caagudeloc@unal.edu.co

Received $8^{\text {th }}$ January 2008/Sent for modification $2^{\text {nd }}$ May 2008/Accepted $28^{\text {th }}$ October 2008

\begin{abstract}
Objective Examining the power (ability) of classical epidemiological estimators to rate inequality in health in univariate and composite ways.

Methods Ecological study. Ratio, excess risk, attributable risk (AR) and relative difference were the estimators used for showing disparities; all of them were weighted by population size. Kappa concordance coefficient was used between weighted estimators and weighted Gini coefficients for each health outcome used. Cumulative variance at first factor in principal component analysis was used for determining the estimators' suitability for use in a composite index. 24 high-income OECD (Organisation for Economical Cooperation and Development) countries' data for 1998-2002 were included. Such data was obtained from OECD health data for 2004 ( $3^{\text {rd }}$ edition). Data concerning child mortality and gross domestic product (GDP) was obtained from World Development Indicators for 2005 on CD-ROM.The main outcomes compared amongst countries were: maternal mortality, child mortality, infant mortality, low birthweight, life-expectancy, measles' immunisation and DTP immunisation.

Results Ratio and AR ranked maternal mortality as being the condition having the most disparity; risk excess ranked vaccination programmes and relative difference ranked low birth-weight as being the worst conditions. There was concordance in the ranking of inequities amongst ratio, AR and Gini coefficients $(p<0.05)$. Cumulative variance in the first factor was higher for ratio and AR when they were used for constructing a composite index.

Conclusions Ratio and AR were better than risk excess and relative difference for measuring disparities in health and constructing composite inequity in health indexes.
\end{abstract}

Key Words: Health status indicator, world health, health inequality, developed country (source, MeSH, NLM). 


\section{RESUMEN}

Objetivo Evaluar la capacidad de la Razón (R), exceso de riesgo (ER), fracción atribuible (FA) y diferencia relativa (DR) para medir las desigualdades en salud. Metodos Estudio ecológico. Se ponderó por el tamaño de la población. La concordancia por indicador entre estimadores y coeficiente de Gini (Gini) se evaluó con coeficiente Kappa. La varianza acumulada en el primer factor (análisis de componentes principales) fue utilizada para evaluar la capacidad de los estimadores para ser utilizados en un índice compuesto. 24 Países de Alto Ingreso (según Banco Mundial) entre 1998 y 2002, fueron incluidos. Los datos se obtuvieron del OECD Health Data, 2004 y del World Development Indicators-2005. Los indicadores comparados entre los países fueron: Mortalidad materna, mortalidad en niños menores de 5 años, mortalidad infantil, bajo peso al nacer, expectativa de vida al nacer, inmunización contra sarampión y contra DTP.

Resultados $\mathrm{R}$ y FA posicionaron la mortalidad materna como la condición de mayor disparidad, ER posicionó los programas de vacunación y DR posicionó el bajo peso al nacer como la peor condición. Hubo concordancia en el posicionamiento de las desigualdades entre R, FA y Gini $(p<0.05)$. La varianza acumulada en el primer factor fue mayor para R y FA, cuando ellos se utilizaron para construir un indicador compuesto.

Conclusiones $\mathrm{R}$ y la FA atribuible son mejores que el ER y la DR para medir desigualdades en salud entre países y para construir un indicador de inequidad en salud compuesto.

Palabras Clave: Indicadores de salud, salud mundial, desigualdades en la salud, países desarrollados (Fuente: DeCS, BIREME)

I nequality in health has existed and been tolerated within and between countries for many years (1). The problem of overall inequity has been measured using indicators such as the Gini Coefficient and Lorenz Curve thereby allowing researchers to know how a condition (especially money) is distributed amongst a particular population. Other authors have used this methodology for estimating concentration curves and index (2-8). The discussion about how to measure equity in health is still ongoing. However, equity and equityin-health should be considered when countries make interventions and especially interventions in health.

This work was aimed at examining classical epidemiological estimators' ability to rate inequality-in-health (in univariate and composite ways) in countries having low expected inequality in health given the existence of such epidemiological estimators and considering that they can be used to show differences in populations. 


\section{METHODOLOGY}

This was an ecological study. Seven general health or general disease indicators were included (six of them suggested in the Millennium Development Goals) (9). The indicators used were: maternal mortality (per 100,000 live births), child mortality (per 1,000 children), infant mortality (per 1,000 live births), low birthweight (percentage of all live births), life-expectancy (years at birth), measles immunisation (percentage of children immunised) and DTP immunisation (\% of children immunised). The epidemiological estimators used to show disparities were: ratio, risk excess, AR and relative difference. The latter method was taken from the methodology used for estimating the variables used to construct the Human Development Index (HDI) (10) which we used for validating two indicators of economic and health gaps (11). Twenty-four high-income OECD (Organisation for Economical Cooperation and Development) countries, so classified by the World Bank, were selected. Data was obtained from OECD health data 2004 ( $3^{\text {rd }}$ edition) (12); 1998 to 2002 were the years selected. Data regarding child mortality and gross domestic product (GDP) were obtained from the 2005 World Development Indicators on CD-ROM (13). In some cases, blank spaces had to be filled in with data from the previous year. In the case of maternal mortality ratio, a value of 1 per 100,000 live births was assigned as minimum because the value 0 (Iceland) produced error when dividing by zero.

\section{Defining epidemiological measurements}

Risk ratio (RR) is defined as the probability of developing a disease in people exposed to it compared to that of non-exposed people (14). It was estimated as $\mathrm{RR}=$ country rate/lowest country rate in case of negative outcomes and $\mathrm{RR}=$ country rate/best country rate in case of positive outcomes.

Excess risk (ER) is an absolute measurement of risk (sometimes called risk difference). It was estimated as $\mathrm{ER}=$ country rate-lowest country rate for negative outcomes or ER=highest country rate-country rate for positive outcomes.

Attributable fraction (AR) is defined as being the amount or proportion of disease incidence which could be attributed to specific exposure, meaning actually living in each country studied and not in countries having the best indicators. It is a relative risk measurement $(14,15)$. Each country was considered as being exposed and the country having the lowest rate was considered to be the non-exposed group. The formula used was AR $=(($ country rate-lowest rate)/country rate)*100 for negative outcomes and $\mathrm{AR}=$ (highest 
country rate-country rate)/highest country rate for positive outcomes. Equation (5) was used for positive outcomes such as immunisation coverage or life-expectancy. Interpreting these results implied that "living in the target country increased the risk of not being covered, or of having lower lifeexpectancy, compared to the best country in the region.”

Relative difference to total difference ratio (RD) is a relative measurement of risk in which the ratio is established by using the absolute difference between the best and worst countries being compared. $\mathrm{RD}$ is estimated as: $\mathrm{RD}=$ (country rate-lowest country rate)/(highest country rate-lowest country rate)*100 in case of negative outcomes and $\mathrm{RD}=$ (highest country ratecountry rate)/( highest country rate-lowest country rate)*100 for positive outcomes.

All epidemiological measurements were adjusted for population size (weighted) and a summary estimation was made for each of them (summarised and weighted estimator - SWE) using the following equation: $\mathrm{SWE}=\sum$ (crude estimations per country)*(n/N), where $n$ is the respective country's population and $\mathrm{N}$ is total OECD countries' population for that respective year. A consistency test (Kappa) was used for evaluating agreement between positions of inequity estimated by SWE and Gini coefficients. Gini coefficients for lifeexpectancy were estimated using the cumulative percentage of years expected to be lived at birth with the cumulative percentage of births in the same year, based on previous work (16). Gini coefficients were based on Schneider et al., (5). Principal component analysis (PCA) was used for determining which SWE had the highest variance represented in the first factor (CV1) and cut-off point (CV). Kaiser's eigenvalue rule and Cattell's scree test were used for defining the cut-off point. In cases where they disagreed, the cut-off point was selected using the factor nearest to one. PCA was done with weighted and non-weighted measurements. Some components did not have normal distribution (maternal mortality ratio for 1998, 199, 2000, 2001 and measles immunisation coverage for 1998); we therefore preferred to use the median and 95\% confidence interval (CI). The database was constructed and Gini coefficients and Lorenz curves estimated using Excel (17). STATA version 8.1 was used for statistical analysis.

\section{RESULTS}

The countries included had between $78 \%$ and $79 \%$ of the world's GDP, expressed in constant dollars for 2000, and $57 \%$ to $54 \%$ when this was based on GDP 
adjusted for parity of purchasing power (PPP). When the median was used, child mortality rate was the only indicator which showed a stable tendency throughout the five-year study period (Table 1). All other indicators oscillated in both median value and $95 \%$ CI. However, some countries were in worse positions than the $95 \%$ CI's lower or higher limits, depending on whether the indicator was negative or positive. For example, countries like Belgium, France, Denmark, Korea, Luxembourg and the Netherlands had maternal mortality ratio values higher than 7.9 for 1998 (between 8.6 and 20). A similar situation happened for the other years and indicators. Table 2 gives the best and worst indicators for OECD countries.

The Gini coefficients did not reveal unequal GDP distribution amongst OECD countries (at constant 2000 values); the tendency improved between 1998 and 2002, being $0.1452,0.1396,0.1420,0.1371$ and 0.1359 , respectively. Maternal mortality revealed higher inequality when it was measured using Gini coefficients during the study period. The other Gini coefficients for the health indicators tested did not reveal any inequity in outcome distribution (Tables 3a, 3b).

Table 1. Exploratory analysis of variables selected High-income OECD countries, 1998-2002

\begin{tabular}{|c|c|c|c|c|c|c|c|c|c|c|}
\hline & & 1998 & & 1999 & & 2000 & & 2001 & & 2002 \\
\hline & Me & $\begin{array}{c}95 \% C 1 \\
\text { (Min-Max) }\end{array}$ & Me & $\begin{array}{c}95 \% \mathrm{Cl} \\
\mathrm{Min} / \mathrm{ax})\end{array}$ & Me & $\begin{array}{c}955 \mathrm{Cl} \\
(\mathrm{Mn}-\operatorname{Max})\end{array}$ & $\mathrm{Me}$ & $\begin{array}{c}\text { soscl } \\
\text { (Min-Max) }\end{array}$ & $\mathrm{Me}$ & $\begin{array}{c}\text { 96\%Cl } \\
\text { (Min-Max) }\end{array}$ \\
\hline $\begin{array}{l}\text { Maternal } \\
\text { mortality } \\
\text { ratio }\end{array}$ & 6,9 & $4,5-7,9$ & 5,6 & $3,8-7,9$ & 6,0 & $3,5-7,5$ & 6,5 & $5,1-7,3$ & 62 & $4,7-8,7$ \\
\hline $\begin{array}{l}\text { Intant } \\
\text { mortaity } \\
\text { catio }\end{array}$ & 5.0 & $4,7-5,5$ & 4,8 & $4,4-5,6$ & 5,0 & $4,5-5,4$ & 5,0 & $4,45,3$ & 4.8 & $4,1-5,1$ \\
\hline $\begin{array}{l}\text { Child } \\
\text { mortality rate }\end{array}$ & 62 & $5,7-7$ & 6,2 & $5.5-7$ & 6,0 & $5,0-6,1$ & 6,0 & $5,0-6,1$ & 6.0 & $5-6$ \\
\hline $\begin{array}{l}\text { Life: } \\
\text { expectancy } \\
\text { at birth } \\
\text { (years) }\end{array}$ & 77.9 & $77,3-78,6$ & 78,0 & $77,5-78,9$ & 78,1 & $77,8-79,2$ & 78,5 & $78,1-79,4$ & 78,5 & $78,1-79,5$ \\
\hline $\begin{array}{l}\text { Low birth. } \\
\text { weight (56) }\end{array}$ & 6,1 & $4,8-6,3$ & 6,4 & $4.8-6.5$ & 6,3 & $5,0-6,6$ & 6,4 & $5,46,7$ & 6.5 & $5,5-6,7$ \\
\hline $\begin{array}{l}\text { Dpt } \\
\text { covertures } \\
\text { (\%) }\end{array}$ & 950 & $89,3 \cdot 97,2$ & 95,0 & $88,3 \cdot 97,3$ & 95,0 & $88,0-97$ & 95,0 & $90,4 \cdot 97$ & 54,0 & 90.2 .97 \\
\hline $\begin{array}{l}\text { Measies } \\
\text { immunisation } \\
\text { (W) }\end{array}$ & 90.5 & $86,4-93,4$ & 90,6 & $87,9-96,3$ & 90,8 & $86,3-93$ & 90.6 & $84,9-93,3$ & 91,2 & $85,6-93,5$ \\
\hline
\end{tabular}

The results for each population size-weighted epidemiological estimator are shown in Tables 3a and 3b. Maternal mortality occupied the top position 
for inequality amongst the variables selected when using the ratio for measuring inequality in OECD countries.

Table 2. Best and worst indicators in high-income OECD Countries in five conditions of health and two of health promotion, 1998-2002

\begin{tabular}{|c|c|c|c|c|c|}
\hline & 1998 & 1999 & 2000 & 2001 & 2002 \\
\hline & \multicolumn{5}{|c|}{ Maternal mortality ratio, per 100,000 Fve births } \\
\hline \multirow[t]{2}{*}{ Best } & lceland & Iceland & Iceland & Iceland & Iceland \\
\hline & 0 & 0 & 0 & 0 & 0 \\
\hline \multirow[t]{2}{*}{ Worst } & Korea & Korea & Korea & Korea & Korea \\
\hline & 20 & 20 & 20 & 20 & 20 \\
\hline \multirow{3}{*}{ Best } & \multicolumn{5}{|c|}{ Infant mortality ratio per 1,000 live births } \\
\hline & Iceland & Iceland & Iceland & Iceland & Iceland \\
\hline & 2,6 & 2,4 & 3 & 2,7 & 2,2 \\
\hline \multirow[t]{2}{*}{ Worst } & USA & USA & USA & USA & USA \\
\hline & 7,2 & 7,1 & 6,9 & 6,8 & 6,8 \\
\hline & \multicolumn{5}{|c|}{ Child mortality rate per 1,000 children } \\
\hline Best & Sweden & Sweden & Finland, Iceland, & Finland, Iceland, & Sweden \\
\hline & 4,3 & 3,9 & $\begin{array}{c}\text { Sweden } \\
4,0\end{array}$ & $\begin{array}{c}\text { Sweden } \\
4,0\end{array}$ & 3,9 \\
\hline \multirow[t]{3}{*}{ Worst } & Belgium, & Belgium, & & & \\
\hline & Greece, & Greece, & USA & USA & USA \\
\hline & $\begin{array}{c}\text { Portugal } \\
9,0\end{array}$ & $\begin{array}{c}\text { Portugal } \\
9.0\end{array}$ & 9,0 & 8,2 & 8,0 \\
\hline & \multicolumn{5}{|c|}{ Low birth-weight (\%) } \\
\hline Best & Korea & Korea & Korea & Iceland & Iceland \\
\hline & 3,5 & 3,6 & 3,8 & 3,3 & 3,9 \\
\hline \multirow[t]{2}{*}{ Worst } & Japan & Japan & Japan & Japan & Japan \\
\hline & 8,1 & 8,4 & 8,6 & 8,8 & 9 \\
\hline & \multicolumn{5}{|c|}{ Life-expectancy at birth (years) } \\
\hline Best & Japan & Japan & Japan & Japan & Japan \\
\hline & 80,6 & 80,5 & 81,2 & 81,5 & 81,8 \\
\hline \multirow[t]{2}{*}{ Worst } & Korea & Korea & Korea & Korea & Korea \\
\hline & 74,4 & 75,5 & 75,5 & 76,4 & 76,4 \\
\hline & \multicolumn{5}{|c|}{ Immunisation Dpt coverage (\%) } \\
\hline Best & Korea & Iceland & Sweden & Korea, Sweden & Sweden \\
\hline & 100 & 99,9 & 99 & 99 & 99 \\
\hline \multirow[t]{2}{*}{ Worst } & Japan & Japan & Japan & USA & Canada \\
\hline & 70 & 70 & 70 & 82,1 & 76,8 \\
\hline \multirow{3}{*}{ Best } & \multicolumn{5}{|c|}{ Measles immunisation coverage (\%) } \\
\hline & Iceland & Iceland & Denmark & Japan & Japan \\
\hline & 99 & 99,9 & 99 & 100 & 100 \\
\hline Worst & Italy & italy & Italy & Ireland & Ireland \\
\hline & 55 & 70 & 74,1 & 73 & 73 \\
\hline
\end{tabular}

Source: OECD Health Data, 2004. Child mortality data was taken from World Development Indicators, 2005, World Bank

By contrast, inequality in vaccination programme coverage amongst OECD countries became more important when ER was used, maternal mortality being placed in the lowest position. Maternal mortality assumed the highest inequality of all when AR was used, followed by infant and child mortality. Maternal mortality assumed a middle position amongst all variables when $\mathrm{RD}$ was used, low birth-weight being in first place followed by infant and child mortality and life-expectancy at birth (i.e. using absolute or relative indicators led to a different ordering of some aspects considered to have more inequality than others). 
Inequality was more evident in negative outcomes when only relative measurements were used. However, the results using RD were different from those obtained when using ratio or AR. There was agreement in ranking inequality amongst the different health outcomes studied in terms of ratio, AR and Gini coefficient ( $\mathrm{p}<0.05)$, as can be seen in Tables 3a and 3b.

Table 3a. Weighted epidemiological estimators in five conditions of health and in two health promotion programmes in high-income

\begin{tabular}{|c|c|c|c|c|c|}
\hline & $\begin{array}{c}1998 \\
\text { Value (rank) }\end{array}$ & $\begin{array}{c}1999 \\
\text { Value (rank) }\end{array}$ & $\begin{array}{c}2000 \\
\text { Value (rank) }\end{array}$ & $\begin{array}{c}2001 \\
\text { Value (rank) }\end{array}$ & $\begin{array}{c}2002 \\
\text { Value (rank) }\end{array}$ \\
\hline \multicolumn{6}{|c|}{ Maternal mortality ratio, per 100,000 live births } \\
\hline $\bar{R}$ & $7.25(1)$ & $7,35(1)$ & $7,42(1)$ & $7,46(1)$ & $7,48(1)$ \\
\hline ER & $0.01(7)$ & $0.01(7)$ & $0.01(7)$ & $0,01(7)$ & $0.01(7)$ \\
\hline AF & $83.0(1)$ & $81,6(1)$ & $83.4(1)$ & $83,65(1)$ & $82,99(1)$ \\
\hline RD & $32,91(6)$ & $36,1(6)$ & $36,4(6)$ & $36.6(6)$ & $36.8(6)$ \\
\hline \multirow[t]{2}{*}{ Gini Coetf. } & $0.21(1)$ & $0.25(1)$ & $0.21(1)$ & $0,20(1)$ & $0.21(1)$ \\
\hline & \multicolumn{5}{|c|}{ Infant mortality ratio, per 1,000 live births } \\
\hline $\mathbf{R}$ & $2,15(2)$ & $2.27(2)$ & $1.77(3)$ & $1,93(3)$ & $2,33(2)$ \\
\hline ER & $0,3(5)$ & $0,3(5)$ & $0.23(6)$ & $0,25(5)$ & $0,29(5)$ \\
\hline AF & $50,7(2)$ & $52,8(2)$ & 39,1 (3) & $44,02(3)$ & $53,23(2)$ \\
\hline RD & $64,9(2)$ & $64,8(2)$ & $58,8(2)$ & $61,1(2)$ & $63,6(1)$ \\
\hline \multirow[t]{2}{*}{ Gini Coeff. } & $0.12(2)$ & $0.13(2)$ & $0.13(3)$ & $0,13(2)$ & $0.15(2)$ \\
\hline & \multicolumn{5}{|c|}{ Child mortality rate, per 1,000 children } \\
\hline $\mathbf{R}$ & $1.61(4)$ & $1.75(4)$ & $1.66(4)$ & $1,61(4)$ & $1,6(4)$ \\
\hline ER & $0.26(6)$ & $0,29(6)$ & $0.26(5)$ & $0,24(6)$ & $0.23(6)$ \\
\hline AF & $34.7(4)$ & $40.0(4)$ & $35.2(4)$ & $35,1(4)$ & $34.5(4)$ \\
\hline RD & $55.5(3)$ & $57,3(3)$ & $52.5(4)$ & $58.3(3)$ & $57,0(4)$ \\
\hline \multirow[t]{2}{*}{ Gini Coetf. } & $0,118(3)$ & $0,117(3)$ & $0,144(3)$ & $0,122(3)$ & $0,116(3)$ \\
\hline & \multicolumn{5}{|c|}{ Low birth-weight (\%) } \\
\hline R & $1,94(3)$ & $1,92(3)$ & $1,83(2)$ & $2,14(2)$ & $1,83(3)$ \\
\hline ER & $3.28(3)$ & $3.31(3)$ & $3,16(3)$ & $3,77(3)$ & $3.24(3)$ \\
\hline AF & $46,1(3)$ & $45,64(3)$ & $43,1(2)$ & $51,5(2)$ & $43,1(3)$ \\
\hline RD & $71,2(1)$ & $68,9(1)$ & $65,8(1)$ & $68,5(1)$ & $63,5(2)$ \\
\hline \multirow[t]{2}{*}{ Gini Coeff. } & $0,09(4)$ & $0,09(4)$ & $0,09(4)$ & $0,08(4)$ & $0,09(4)$ \\
\hline & \multicolumn{5}{|c|}{ Life-expectancy at birth (years) } \\
\hline $\mathbf{R}$ & $1.04(7)$ & $1.03(7)$ & $1.04(7)$ & $1,04(7)$ & $1,04(7)$ \\
\hline ER & $2,78(4)$ & $2,55(4)$ & $2,96(4)$ & $2,94(4)$ & $3,13(4)$ \\
\hline AF & $3.45(7)$ & $3,17(7)$ & $3.65(7)$ & $3,61(7)$ & $3.82(7)$ \\
\hline RD & $44.7(4)$ & $51.0(4)$ & $52(5)$ & $57.7(5)$ & $57,9(3)$ \\
\hline Gini Coeff. & $0,009(7)$ & $0.008(7)$ & $0.007(7)$ & $0,005(7)$ & $0,007(7)$ \\
\hline
\end{tabular}

PCA showed that cumulative variance estimated in first factor (CV1) and global cumulated variance (CV) at cut-off point were higher in all weighted estimators compared to non-weighted estimators (Table 4). CV1 was the highest estimator for ratio and AR. AR had the highest cumulative variance for non-weighted estimators at first factor and the highest cumulative variance at cut-off point. However, differences in global cumulative variance were very slight. 
Table 3b. Weighted epidemiological estimators in two health promotion programmes in high-income OECD countries, 1998-2002

\begin{tabular}{|c|c|c|c|c|c|}
\hline & $\begin{array}{l}1998 \\
\text { Value } \\
\text { (rank) }\end{array}$ & $\begin{array}{c}1999 \\
\text { Value (rank) }\end{array}$ & $\begin{array}{l}2000 \\
\text { Value } \\
\text { (rank) }\end{array}$ & $\begin{array}{c}2001 \\
\text { Value (rank) }\end{array}$ & $\begin{array}{c}2002 \\
\text { Value (rank) }\end{array}$ \\
\hline & \multicolumn{5}{|c|}{ Immunisation Dpt coverage (\%) } \\
\hline Ratio & $1,15(5)$ & $1,16(5)$ & $1,12(5)$ & $1,12(5)$ & $1,12(5)$ \\
\hline RExcess & $12,2(1)$ & $12,3(1)$ & $10,4(1)$ & $9,7(1)$ & $10,2(1)$ \\
\hline AFraction & $12.2(5)$ & $12,3(5)$ & $10,5(5)$ & $9,88(5)$ & $10,3(5)$ \\
\hline RDifference & $40,8(5)$ & $41,3(5)$ & $57,9(3)$ & $57,8(4)$ & $45,9(5)$ \\
\hline \multirow[t]{2}{*}{ Gini Coetf. } & $0,05(5)$ & $0,05(5)$ & $0,04(5)$ & $0,04(5)$ & $0,04(5)$ \\
\hline & \multicolumn{5}{|c|}{ Measles immunisation coverage (\%) } \\
\hline Ratio & $1,14(6)$ & $1,12(6)$ & $1,1(6)$ & $1,11(6)$ & $1,1(6)$ \\
\hline RExcess & $10,7(2)$ & $9,9(2)$ & $8,9(2)$ & $9,3(2)$ & $8,83(2)$ \\
\hline Afraction & $10,8(6)$ & $9,95(6)$ & $8,99(6)$ & $9,3(6)$ & $8,83(6)$ \\
\hline RDifference & $24,4(7)$ & $33,2(7)$ & $35,7(7)$ & $34,4(7)$ & $32,7(7)$ \\
\hline Gini Coeff. & $0.03(6)$ & $0.03(6)$ & $0,03(6)$ & $0,03(6)$ & $0.02(6)$ \\
\hline
\end{tabular}

Table 4. Epidemiological estimators' cumulated variance at first factor and cut-off point for high-income OECD countries, 1998-2002

\begin{tabular}{cccccccccccc}
\hline & \multicolumn{4}{c}{1998} & \multicolumn{1}{c}{1999} & \multicolumn{2}{c}{2000} & \multicolumn{2}{c}{2001} & \multicolumn{2}{c}{2002} \\
\hline $\begin{array}{c}\text { Epidemiological } \\
\text { estimators }\end{array}$ & CV1 & CV & CV1 & CV & CV1 & CV & CV1 & CV & CV1 & CV \\
Ratio & 0,37 & 0,79 & 0,37 & 0,75 & 0,38 & 0,79 & 0,4 & 0,78 & 0,4 & 0,79 \\
Risk excess & 0,36 & 0,81 & 0,36 & 0,77 & 0,38 & 0,81 & 0,41 & 0,79 & 0,41 & 0,78 \\
AFraction & 0,41 & 0,8 & 0,41 & 0,78 & 0,41 & 0,82 & 0,46 & 0,8 & 0,45 & 0,79 \\
RDifference & 0,36 & 0,81 & 0,36 & 0,77 & 0,38 & 0,81 & 0,41 & 0,79 & 0,41 & 0,78 \\
Ratio-(weighted) & 0,96 & 0,97 & 0,98 & 0,98 & 0,98 \\
\hline $\begin{array}{c}\text { AFraction } \\
\text { (weighted) }\end{array}$ & 0,86 & 0,89 & 0,92 & 0,92 & 0,93 \\
$\begin{array}{c}\text { RDifference } \\
\text { (weighted) }\end{array}$ & 0,82 & 0,88 & 0,91 & 0,91 & 0,92 \\
$\begin{array}{c}\text { RExcess } \\
\text { (weighted) }\end{array}$ & 0,82 & 0,88 & 0,91 & 0,91 & & 0,92 \\
\hline
\end{tabular}

\section{DISCUSSIÓN}

Equity-in-health in this study has been assumed to be, "equal outcomes or results in health in equal populations," based on Tawney, Shiell and Le Grand's arguments about using results or outcomes when evaluating inequality (18-20). It does not matter how investment in health (vertical or horizontal) is made. Put simply, people do not have to die because they are women, poor, richer, black or live in a different geographical region. The existence of countries having rates, ratios or coverage outside the expected median confidence interval limits suggests a substantial difference between them, respecting those distributed within the confidence interval. However, the size of disparity in health within OECD countries could not be shown with just these results. In other words, showing that there are countries in extreme positions (or outliers) is not enough to show the magnitude of disparity in the region where the studied countries are located, nor would just using the worst value o show the greatest disparity as it would not reflect real 
disparity size. The existence of individual disparities justified the need for SWE measurement of each indicator's overall disparity within the countries being studied. SWE per se reflected inequality-in-health in each indicator used in high-income OECD countries. Maternal mortality presented an SWE-ratio higher than 7.0, meaning that the ratio between each group of countries and the best of them all was 7 to 1 . Child mortality inequality which could be explained by the differences between countries was between $52 \%$ and $58 \%$ (Tables 3a, 3b). However, maternal mortality ratio alone or just the child mortality rate cannot show the level of total inequality-in-health existing in these countries. When a composite is going to be made for measuring inequality then SWE should be used as the construct for such composite. SWE ratio and SWE AR ranked the indicators included in the study in almost the same positions as the Gini coefficient ranked them. By contrast, ER and RD did not agree with each other or with the other measurements used.

The next step in this study was to evaluate the estimators' pattern when they were used together in a composite. We used the CV1 and CV explained by each SWE. The best results were returned for SWE ratios and SWE ARs in this study, little difference being seen between them. Another study has used this methodology for comparing four scales' behaviour in measuring inequalities in health, also using variance in the first factor for selecting the best socioeconomic status index (21).

Though ER and RD were similar mathematically, their results should be interpreted in a different way. In fact, PCA results show that using ratios better explains CV1 than using AR. The ratio has the disadvantage that division by zero can happen whilst this cannot occur with AR. RD also has the disadvantage of producing results depending on changes in both numerator and denominator. RD could thus make estimations comparable between countries during the same period; however, it was not useful when comparisons were made between periods because, the gap between the best and worst country could increase (denominator) and the country being studied would stay at the same level. RD would become reduced in this case because the denominator had increased. Comparisons made during the same period would thus be credible, but not so between periods. This was reflected in this study by low birth-weight RD; while the prevalence of children's low birth-weight generally went up, it went down when RD were applied (Tables 1 and 3). Epidemiological estimators are known and used by almost everybody, but not usually for measuring inequality. Keppel et al., have presented a good review about their use in health disparity, but they did not adopt a final position concerning which of them was the best for measuring inequality 
(22). This paper provides the reader with two additional elements which have not been considered before: epidemiological estimators' ability to show and rank disparity in health compared to Gini coefficients when used in a scenario regarding countries where lower (or zero) disparity is expected from them, plus their ability to show total variance when they are going to be used as a "composite."

This study's results suggested using ratios and ARs for estimating disparity in health, given that they agreed with Gini coefficients in ranking inequality and better represented total variance when they were added together. AR and ratios showed better cumulative variance than the other estimators, though each one had high cumulative variance in the first factor when they were weighted. It is also strongly recommended (as usually suggested in epidemiology) weighting summary measurements in cases of measuring populations' disparities-in-health. Keppel et al., have suggested the use of weighted or non-weighted measurements, assuming that non-weighted values imply that what is important is the group itself, regardless of its share of the population, and weighting offers a populationbased perspective on disparity (22). Several authors have written about how to measure disparity and disparities in health (22-24). However, all these proposals were intended to quantify equity in the fields of access, use or income. Keppel et al., (22) have proposed a way for measuring AR which is opposed to the formula which we have used. They used the reference point as denominator in cases in which the reference point was presumed to be lower than the point of interest, calling it "percentage difference" (PD), using the following equation: $\mathrm{PD}=$ (rate of interest-reference point)/(reference point)*100 (22). It is highly probable that differences greater than $100 \%$ will be produced because of the denominator's size. High-income OECD countries were selected because disparity in this kind of country is expected to be small. Even though weighted differences were "slight" there were important disparities between them. It is worrying that the maternal mortality ratio increased from 7.22 to 7.45 during the period being studied or that AR were higher than $80 \%$, meaning that such percentage could be attributed to being from a country different to the country having the lowest maternal mortality ratio. Other authors have shown disparities between countries. For instance, Houweling et al., have studied the relationship between income and child mortality $(21,25)$. Arntzen has studied its relationship with infant mortality in Nordic countries (26).

This study revealed a better pattern for relative estimators (ratio and AR) regarding the amount of variance which they could explain when all SWEs were brought together in a composite. They also agreed with Gini coefficients in ranking inequity, being better than Gini coefficients because they amplified disparity size 
compared to Gini coefficients and were able to show greater disparity where Gini coefficients showed less disparity. Regarding maternal mortality, inequality shown by Gini coefficients was 0,21 to 0,25 whilst using ratio gave 7,2 to 7,48 and AR ranged from $81 \%$ to $83 \%$. The same could be said for low birth-weight in which Gini coefficients had nearly perfect equality (0.092 to 0.095) whilst ratios were between 1,83 and 2,14 and AR ranged from 43,1 \% to 51,5\%. ARs and ratios could also be more easily used for making a bi-dimensional composite, as in the example developed in this study, something which could not be done with Gini coefficients because these are per se bi-dimensional estimators of an area under the Lorenz curve whilst ratio and AR are one-dimensional estimators.

We did not want to validate SWEs joined in an inequality-in-health estimator because we wanted first to prove which SWE measurements could best estimate inequality and which would work better when added to others regarding the same condition. This methodology can only be applied to making comparisons between countries which effectively measure their health status through these indicators. It is true that poor countries do not measure their health status (27) and that these indicators do not reflect the real state of inequity around the world. Just like other ecological studies, this study could lead to an ecologic fallacy in the sense that the observations made have not been linked to individuals but to countries.

We would thus recommend using relative estimators for measuring inequality in health because they better represent variance in the summary measurements built with them, amongst them being the AR and ratio. Even though a new inequality-in-health indicator constructed as a composite of SWEs can be built using the suggested methodology, it should always be fully validated before being used

Acknowledgements. This study was funded by Colciencias (11010418074) and the National University of Colombia.

\section{REFERENCES}

1. Glaser J. Intergroup Bias and Inequity: Legitimizing Beliefs and Policy Attitudes. Social Justice Research. 2005 2005/09//;18(3):257-82.

2. Robinson JC. Consolidation and the transformation of competition in health insurance. Health Aff (Millwood). 2004 Nov-Dec;23(6):11-24.

3. Hidayat B, Thabrany H, Dong H, Sauerborn R. The effects of mandatory health insurance on equity in access to outpatient care in Indonesia. Health Policy Plan. 2004 Sep;19(5):322-35. 
4. Gattini C, Sanderson C, Castillo-Salgado C. Using different indicators of preventable mortality as an approach to measuring health inequalities in Chilean municipalities. Rev Panam Salud Publica. 2002 Dec;12(6):454-61.

5. Schneider MC, Castillo-Salgado C, Bacallao J, Loyola E, Mujica OJ, Vidaurre M, et al. Methods for measuring inequalities in health. Rev Panam Salud Publica. 2002 Dec;12(6):398-414.

6. Sandiford P, Salvetto M. Health inequalities in Panama. Gac Sanit. 2002 Jan-Feb;16(1):70-81.

7. Peacock D, Devlin N, McGee R. The horizontal equity of health care in New Zealand. Aust N Z J Public Health. 1999 Apr;23(2):126-30.

8. Lairson DR, Hindson P, HauquitzA. Equity of health care in Australia. Soc Sci Med. 1995 Aug;41(4):47582.

9. WHO. Health and the Millennium Development Goals. Paris: World Health Organization; 2005.

10. United Nations DP. Human Development Report 1999. New York: Oxford University Press, Inc; 1999.

11. Eslava Schmalbach JH, Buitrago Gutierrez G. Two indicators for measuring the countries' gap between health and economy. Rev Salud Publica (Bogota). 2004 May-Aug;6(2):183-98.

12. OECD. Health Data 2004, Third edition. A comparative analysis of 30 countries. Paris: OECD-Eco Santé Software; 2004.

13. World-Bank. Colombia. Fiscal Strenthening Program. Policy Note on Health. New York; 2001. p. 36 págs.

14. Gordis L. Epidemiology. 3rd ed. Philadelphia: Elsevier Saunders; 2004.

15. Rothman K. Measuring disease occurrence and causal effects. In: Rothman K, editor. Epidemiology An introduction. New York: Oxford University Press; 2002. p. 223.

16. Llorca J, Prieto Salceda D, Delgado-Rodriguez M. [The measurement of inequalities in age of death: calculating the Gini Index based on mortality tables]. Rev Esp Salud Publica. 2000 Jan-Feb;74(1):5-12.

17. Schneider MC, Castillo-Salgado C, Bacallao J, Loyola E, Mujica OJ, Vidaurre M, et al. [Template to estimate Gini coefficient and Lorenz Curve]. 2002 Dec [cited 2002]

18. Tawney R. Equality. London: George Allen \& Unwin Ltd.; 1964 (1931).

19. Shiell A. Health outcomes are about choices and values: an economic perspective on the health outcomes movement. Health Policy. 1997 1997/1;39(1):5-15.

20. Le Grand J. The strategy of equality : redistribution and the social services. London ; Boston: $\mathrm{G}$. Allen \& Unwin; 1982.

21. Houweling TA, KunstAE, Mackenbach JP. Measuring health inequality among children in developing countries: does the choice of the indicator of economic status matter? Int J Equity Health. 2003 Oct 9;2(1):8.

22. Keppel K, Pamuk E, Lynch J, Carter-Pokras O, Kim I, Mays V, et al. Methodological issues in measuring health disparities. Vital Health Stat 2. 2005 Jul(141):1-16.

23. Braveman PA, Egerter SA, Cubbin C, Marchi KS. An Approach to Studying Social Disparities in Health and Health Care. Am J Public Health. 2004 December 1, 2004;94(12):2139-48.

24. Gakidou E, King G. Measuring total health inequality: adding individual variation to group-level differences. Int J Equity Health. 2002 Aug 12;1(1):3.

25. Houweling TA, Kunst AE, Looman CW, Mackenbach JP. Determinants of under-5 mortality among the poor and the rich: a cross-national analysis of 43 developing countries. Int J Epidemiol. 2005 Sep 13.

26. Arntzen A, Nybo Andersen AM. Social determinants for infant mortality in the Nordic countries, 1980-2001. Scand J Public Health. 2004;32(5):381-9.

27. Attaran A. An Immeasurable Crisis? A Criticism of the Millennium Development Goals and Why They Cannot Be Measured. PLoS Med. 2005 Sep 13;2(10):e318. 